\title{
Effects of air temperature and velocity on the drying kinetics and product particle size of starch from arrowroot (Maranta arundinacae)
}

\author{
Alvin R. Caparanga ${ }^{1, *}$, Rachael Anne L. Reyes ${ }^{2}$, Reiner L. Rivas ${ }^{1}$, Flordeliza C. De Vera ${ }^{1}$, Vithyacharan Retnasamy ${ }^{2}$ \\ and Hasnizah Aris ${ }^{2}$ \\ ${ }^{1}$ School of Chemical Engineering and Chemistry, Mapúa University 658 Muralla St., Intramuros, Manila 1002, Philippines \\ ${ }^{2}$ School of Microelectronic Engineering, University Malaysia Perlis (UniMAP), Kampus Alam, Pauh Putra, 02600 Arau, Perlis, \\ Malaysia.
}

\begin{abstract}
This study utilized the $3^{\mathrm{k}}$ factorial design with $\mathrm{k}$ as the two varying factors namely, temperature and air velocity. The effects of temperature and air velocity on the drying rate curves and on the average particle diameter of the arrowroot starch were investigated. Extracted arrowroot starch samples were dried based on the designed parameters until constant weight was obtained. The resulting initial moisture content of the arrowroot starch was $49.4 \%$. Higher temperatures correspond to higher drying rates and faster drying time while air velocity effects were approximately negligible or had little effect. Drying rate is a function of temperature and time. The constant rate period was not observed for the drying rate of arrowroot starch. The drying curves were fitted against five mathematical models: Lewis, Page, Henderson and Pabis, Logarithmic and Midili. The Midili Model was the best fit for the experimental data since it yielded the highest $\mathrm{R}^{2}$ and the lowest RSME values for all runs. Scanning electron microscopy (SEM) was used for qualitative analysis and for determination of average particle diameter of the starch granules. The starch granules average particle diameter had a range of $12.06-$ $24.60 \mu \mathrm{m}$. The use of ANOVA proved that particle diameters for each run varied significantly with each other. And, the Taguchi Design proved that high temperatures yield lower average particle diameter, while high air velocities yield higher average particle diameter.
\end{abstract}

\section{Introduction}

Drying is the oldest preservation technique and one of the most common methods used in removing moisture content. It is used in various industries since it is cost effective and the most practical means of preservation [7]. The drying process employed affects the quality of a dried product. Drying methods used for root crops and starches include solar drying, drum drying, spray drying, freeze drying, microwave drying and hot air drying [5].

Maranta arundinacae L. (Arrowroot) is a root crop coming from the genus maranta which is a large, perennial herb found in rainforest habitats. The crop is cultivated for starch, commonly called as arrowroot, obtained from the rhizomes or rootstock of the plant. Arrowroot starch is widely considered as a nutritious starch and can be easily digested [3]. Some of its characteristics include, being not weakened by acidic ingredients, has a more neutral taste, and it is not affected by freezing [2]. When full grown, its composition in 100 parts include $26 \%$ starch, $6 \%$ woody fiber, $1.5 \%$ albumin, $1 \%$ gummy extract, volatile oil and salts, and $65.5 \%$ water [8]. Extensive extraction and drying is needed to extract pure arrowroot starch and remove most of its water content.
Different studies regarding the drying kinetics of other root crops and other starches have been made. However limited studies about kinetic drying of arrowroot have been reported. Therefore, the study aims to determine the effects of temperature and varying air condition rates on the drying characteristics and particle diameter of arrowroot using a tray dryer. This research will fit a suitable model that represents its drying behaviour and evaluate its initial moisture content and drying rate curves.

Conducting this study will help improve the understanding of the drying phenomenon involve in the drying of arrowroot as well as contribute to existing studies regarding the root crop. Determination of the drying characteristics of arrowroot will aid in predicting and improving its shelf life, which is mostly important for novelty foods that are easily spoiled. The results of this study can be used by other researchers in designing a better drying process of arrowroot through the optimization of present techniques and technologies available in the industry.

The drying characteristics of Maranta arundinacae $L$. is the only variety of arrowroot that will be used in this study. Drying procedures will be conducted using the $3^{\mathrm{k}}$ factorial design with $\mathrm{k}=2$ for the two factors to be

* Corresponding author: arcaparanga@mapua.edu.ph 
varied namely, temperatures at $30,48 \& 65^{\circ} \mathrm{C}$, and air velocity at $0.4,0.5 \& 0.6 \mathrm{~m} / \mathrm{s}$ at constant relative humidity. The starch property to be fitted in the models proposed will be the moisture ratio plotted against the drying time. The Lewis, Page, Henderson and Pabis, Midilli and Logarithmic Models will be the only models used for curve fitting on the drying characteristics of the starch. The flavour and nutritional aspects of the arrowroot will not be addressed in this study. Also, it should be noted that the economic aspect will not be considered as well.

\section{Methodology}

\subsection{Preparation of Arrowroot}

The arrowroot was first verified by the Botany Department of the National Museum of the Philippines so as to authenticate its species. The arrowroot sample was bought from the local municipality of Cuyo, Palawan and was stored at room temperature not exceeding $30^{\circ} \mathrm{C}$. The arrowroots were then washed with tap water and then cleaned of the paper-like scale. After trimming, the arrowroots were washed again and then drained.

\subsection{Extraction of the liquid}

The arrowroot was cut into small pieces and grounded using a blender. The milky liquid obtained was passed through a coarse cloth or hair sieve and the pure starch, which is insoluble, was allowed to settle at the bottom. Decantation was used in order to separate the liquid from the insoluble powder.

\subsection{Initial moisture content determination}

The initial moisture content, $X_{0}$, of the insoluble powder was determined by placing freshly decanted and dried samples of about $3.5 \mathrm{~g}$ to $5 \mathrm{~g}$ in a crucible inside an oven dryer at $105{ }^{\circ} \mathrm{C}$ then weighed every 40 minutes until constant. $\mathrm{X}_{\mathrm{o}}$ was calculated using equation 1 , where $\mathrm{W}_{\mathrm{i}}$ is the initial weight of the sample and $\mathrm{W}_{\mathrm{f}}$ is the final weight of the sample. Moisture analysis was done in triplicate.

$$
X_{o}=\frac{W_{i}-W_{f}}{W_{i}} x 100
$$

\subsection{Drying equipment and drying procedure}

The equipment used was a computer controlled tray dryer (UOP8MKII) located at the pilot plant of the school. Decanted starch extracted from samples weighing approximately $2 \mathrm{~kg} \pm$ each, was spread evenly in a lightweight coated aluminum tray then placed in a tray dryer subjected to moisture analysis at constant relative humidity. The drying procedure followed the $3^{\mathrm{k}}$ factorial design, with $\mathrm{k}$ being the two factors being varied namely, temperature and air velocity. Table 1 shows the factorial design used for the experiment, along with the temperature and air velocity values used. The drying progress was followed by weighing the samples, which was done electronically by the equipment since it has a built in integrated electronic weight measurement. The drying process was set to stop once the measured weight of the sample by the equipment becomes constant.

\begin{tabular}{|l|l|l|}
\hline Run no. & $\begin{array}{l}\text { Temperature }\left(^{\mathrm{o}}\right. \\
\mathrm{C})\end{array}$ & $\begin{array}{l}\text { Air velocity } \\
(\mathrm{m} / \mathrm{s})\end{array}$ \\
\hline 1 & 30 & 0.4 \\
\hline 2 & 30 & 0.5 \\
\hline 3 & 30 & 0.6 \\
\hline 4 & 48 & 0.4 \\
\hline 5 & 48 & 0.5 \\
\hline 6 & 48 & 0.6 \\
\hline 7 & 65 & 0.4 \\
\hline 8 & 65 & 0.5 \\
\hline 9 & 65 & 0.6 \\
\hline
\end{tabular}

\subsection{Drying rate curves}

The equilibrium moisture content, $X^{*}$, at constant relative humidity was set as the constant weight generated by the dryer. The free moisture content at a certain time will be calculated using equation 2 ,

$$
X=\frac{W-B D S}{B D S}
$$

where $\mathrm{X}$ is the free moisture content at a certain time, W is the mass of the wet sample and BDS is the mass of the calculated bone dry sample using the initial moisture content, $\mathrm{X}_{0}$. This free moisture content was then plotted against time to obtain the equation that was used to get the drying rate. The drying rate was obtained using equation

$$
R=-\left(\frac{W}{B D S}\right)\left(\frac{d X}{d t}\right)
$$

where $\mathrm{R}$ is the drying rate in $\mathrm{g}_{2} \mathrm{O} / \mathrm{g}$ BDS-min and $\mathrm{dx} / \mathrm{dt}$ as the slope of the tangent line drawn on the $\mathrm{X}$ vs. $\mathrm{t}$ curve. Moisture content was also plotted against the drying rate to determine the constant rate of drying, $R_{c}$ and the critical moisture content, $\mathrm{X}_{\mathrm{c}}$.

\subsection{Drying Models}

With the data obtained from the experiment and the determination of initial moisture content, the moisture ratio per minute of drying was determined then fitted using 5 models, namely: Lewis, Page, Henderson and 
Pabis, Midili and Logarithmic. These mathematical models along with their corresponding equations are shown in Table 2. Regression analysis was performed using the drying models and the experimental data. The best fit model was chosen based on the highest value of $\mathrm{R}^{2}$ and lowest RSME values.

Table 2. Thin layer drying models to be used in the experiment [11]

\begin{tabular}{|l|l|}
\hline Model Name & Equation \\
\hline Lewis & $\mathrm{M}_{\mathrm{R}}=\exp (-\mathrm{kt})$ \\
\hline Page & $\mathrm{M}_{\mathrm{R}}=\exp \left(-\mathrm{kt}^{\mathrm{n}}\right)$ \\
\hline Henderson and Pabis & $\mathrm{M}_{\mathrm{R}}=\mathrm{a} \exp (-\mathrm{kt})$ \\
\hline Midili & $\mathrm{M}_{\mathrm{R}}=\mathrm{a} \exp \left(-\mathrm{kt}^{\mathrm{n}}\right)+\mathrm{bt}$ \\
\hline Logarithmic & $\mathrm{M}_{\mathrm{R}}=\mathrm{a} \exp (-\mathrm{kt})+\mathrm{c}$ \\
\hline
\end{tabular}

\subsection{Scanning Electron Microscope (SEM) and Statistical Analysis Data}

Particle diameter of the dried starch granules were measured using a scanning electron microscope (JEOL JSM-5310, Japan). Micrographs were generated for each run along with measured particle diameters. Statistical analysis of data was applied to the obtained particle diameters to determine the significance of the varying conditions for each run. All values will be reported as mean \pm standard deviation of 3 trials. Oneway analysis of variance (ANOVA) using Minitab was conducted to determine if there are significant differences between means and design of experiment (DOE) using Taguchi Design was applied to determine the significance of the varying conditions to the particle diameter of the sample.

\section{Results and Discussion}

\subsection{Initial Moisture Content}

From Figure 1, the \% moisture removed from the fresh sample becomes constant at $49.4 \%$. The initial moisture content of the fresh sample can then be assumed to be equal to this value. In a previous study of arrowroot starch, it was found that the initial moisture content is equal to $40.4 \%$ [1]. The higher value obtained for the initial moisture content is due to the arrowroot sample used in this study was not fully grown which corresponds to a higher water content of the crop.

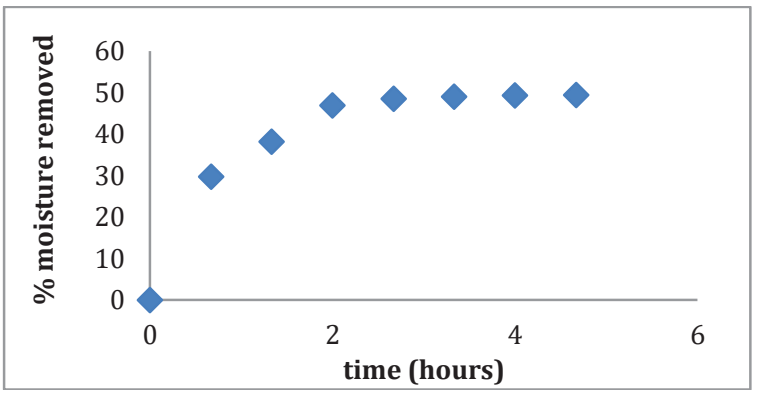

Fig. 1. Percent moisture removed vs. time
The final moisture content of the dried samples was also obtained to check whether they fall within $10 \%$, since microbial damage, non - enzymatic browning and enzymatic reactions occur at moisture contents above $10 \%$ for dried food materials [10]. Table 3 shows the final moisture content obtained for each run of the dried samples.

Table 3. Final moisture content of dried arrowroot starch samples

\begin{tabular}{|c|c|}
\hline Run no. & Final moisture content (\%) \\
\hline 1 & 9.9167 \\
\hline 2 & 9.2889 \\
\hline 3 & 8.7016 \\
\hline 4 & 9.9443 \\
\hline 5 & 7.6416 \\
\hline 6 & 9.1049 \\
\hline 7 & 4.5600 \\
\hline 8 & 4.1736 \\
\hline 9 & 5.7636 \\
\hline
\end{tabular}

\subsection{Drying Rate Curves}

Figures 2 and Figure 3 shows the plot of free moisture content versus time for runs 2 and 5 respectively. In reference with these figures, it is evident that, at a certain time, the free moisture suddenly rises then falls again. This trend can be seen in other runs as well and is due to the uneven distribution of the starch in the tray during drying [1]. Comparing Figures 2 and 3, it can be inferred that different drying temperatures operating at the same air velocity corresponds to different drying times. Runs having higher temperatures result in lower drying time compared to runs having lower temperatures. Thus, an increase in drying temperature increases the amount of moisture removed at a certain time.

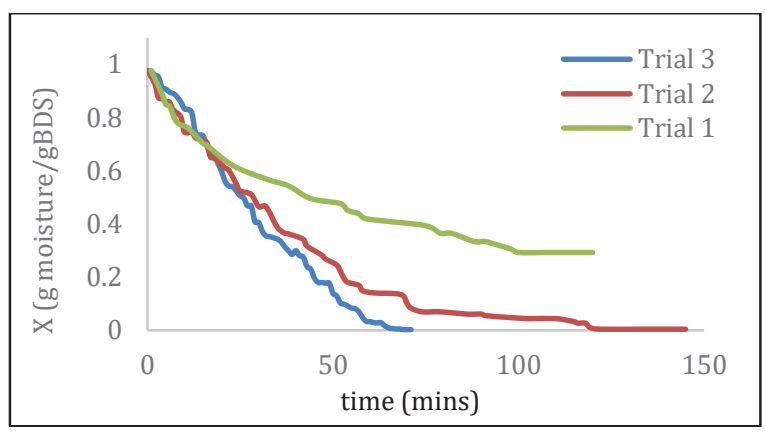

Fig. 2. Free moisture content, $X$ vs. time for run 2 


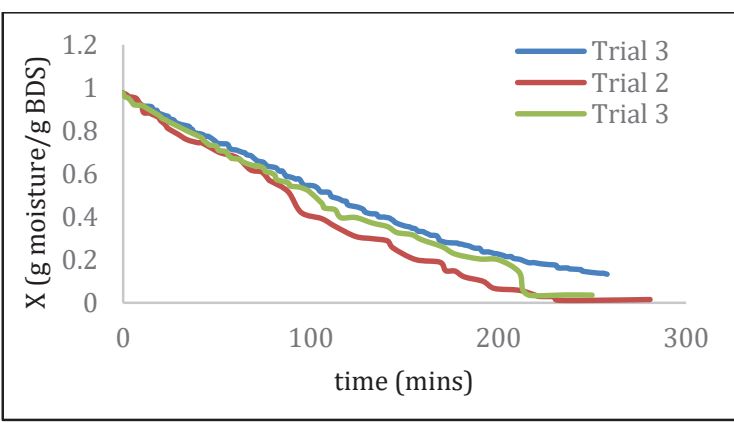

Fig. 3. Free moisture content, $\mathrm{X}$ vs. time for run 5

Shown in Figures 4 and 5 and are the drying rate curves plotted against moisture content of runs 2 and 5. From these figures, it is observed that the drying rate of the sample has no constant rate period. It only has a continuous falling rate period until it reaches its equilibrium moisture content. Starchy foods have no true constant drying rate period, however the concept of constant rate is still used as an approximation [4].

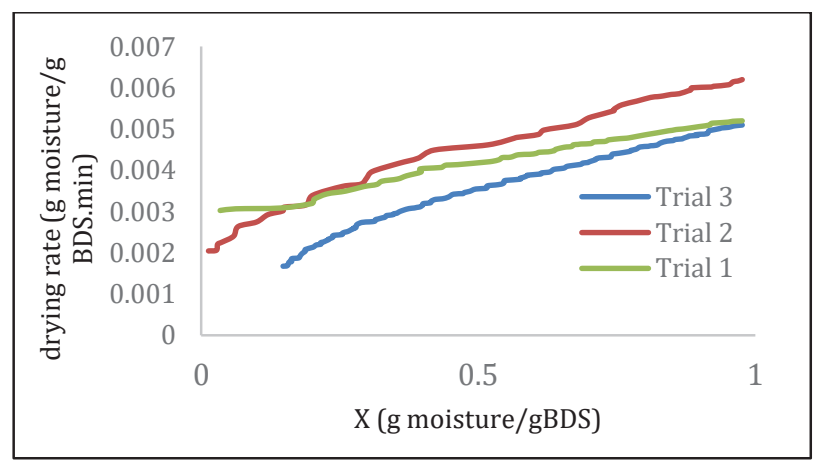

Fig. 4. Drying rate vs. moisture content (wet basis) of run 2

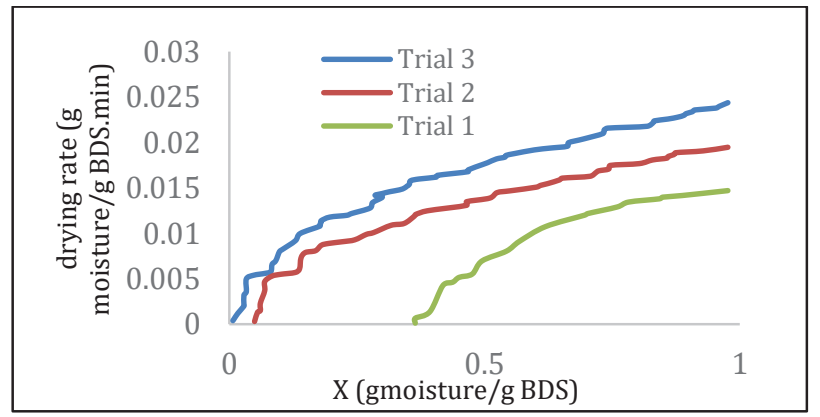

Fig. 5. Drying rate vs. moisture content (wet basis) of run 5

In Table 4, the drying rates per run with varying conditions, is shown. From here, it can be observed that as the temperature increases, the drying rate also increases It is also observed that air velocity has no or little effect in the value of the drying rate as the value is approximately constant with different values of air velocities. Since air velocity has little effects in rate of moisture removal, based from the moisture content vs. time curve, it would imply that its effects on the value of the drying rate would be negligible. This then implies that the drying rate is a strong function of temperature and time.
Table 4. Comparison of drying rates of different runs

\begin{tabular}{|c|c|c|c|}
\hline $\begin{array}{c}\text { Temperature } \\
\left({ }^{\circ} \mathrm{C}\right)\end{array}$ & $\begin{array}{l}\text { Air velocity } \\
(\mathrm{m} / \mathrm{s})\end{array}$ & $\begin{array}{l}\text { Run } \\
\text { no. }\end{array}$ & $\begin{array}{l}\text { Drying } \\
\text { rate }(\mathrm{g} \\
\text { moisture/g } \\
\text { BDS.min) }\end{array}$ \\
\hline \multirow{3}{*}{30} & 0.4 & 1 & $\begin{array}{c}0.0055 \pm \\
0.0005\end{array}$ \\
\hline & 0.5 & 2 & $\begin{array}{c}0.0055 \pm \\
0.0006\end{array}$ \\
\hline & 0.6 & 3 & $\begin{array}{c}0.0053 \pm \\
0.0020\end{array}$ \\
\hline \multirow{3}{*}{48} & 0.4 & 4 & $\begin{array}{c}0.0179 \pm \\
0.0011 \\
\end{array}$ \\
\hline & 0.5 & 5 & $\begin{array}{c}0.0195 \pm \\
0.0048\end{array}$ \\
\hline & 0.6 & 6 & $\begin{array}{c}0.0145 \pm \\
0.0010 \\
\end{array}$ \\
\hline \multirow{3}{*}{65} & 0.4 & 7 & $\begin{array}{c}0.0252 \pm \\
0.0081\end{array}$ \\
\hline & 0.5 & 8 & $\begin{array}{c}0.0204 \pm \\
0.0023\end{array}$ \\
\hline & 0.6 & 9 & $\begin{array}{c}0.0227 \pm \\
0.0056\end{array}$ \\
\hline
\end{tabular}

\subsection{Mathematical Modelling of Arrowroot}

The data on moisture ratio versus drying time obtained is plotted and fitted on the five mathematical models chosen. Figure 6 shows the plotted models for run 5 . The best fit model is selected based from $\mathrm{R}^{2}$ and RSME values. Based on the computed values, it was observed that the Midili Model gave the best fit on the experimental data since it yielded the highest $\mathrm{R}^{2}$ value and lowest RSME value. This indicates that the temperature has the greatest effect in the drying rate since the coefficients of the Midili Model are dependent on the drying air temperature [6].

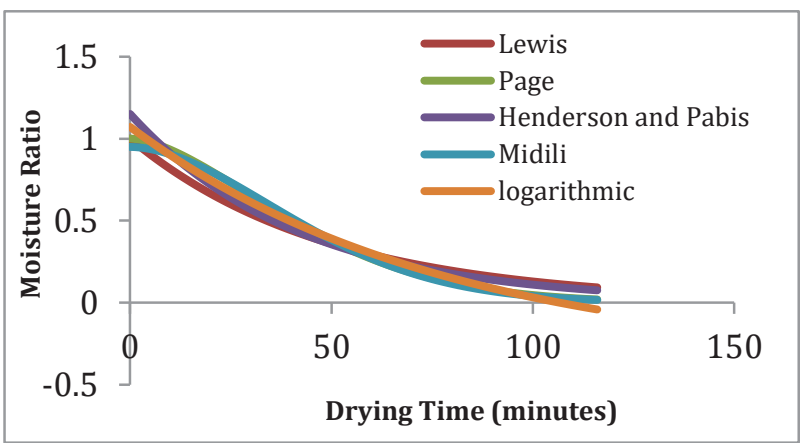

Fig. 6. Moisture Ratio versus Time for Run 5 with the temperature at $48^{\circ} \mathrm{C}$.

\subsection{Scanning Electron Microscopy and Statistical Analysis}

Scanning electron microscopy was used to determine the range of the average particle diameter of the arrowroot granules along with the effect of temperature and air velocity on the particle diameter. Figures 7 show the micrographs from the scanning electron microscopy. From these figures, it can be seen that the arrowroot starch granules are oval in shape and show an off - 
center hilum similar to that of potato, canna and sago starches [9]. The average particle diameter for each run was determined by selecting random samples of granules from the micrograph and measuring the individual particle size using the scale of figures on the left side if need be. The obtained particle diameter for each run is within the general range of $10-50 \mu \mathrm{m}$ for arrowroot starch granules [9]

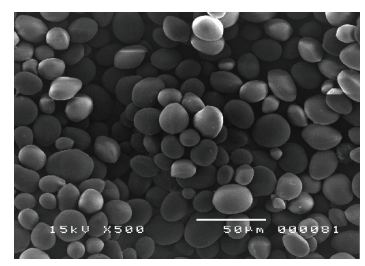

(a)

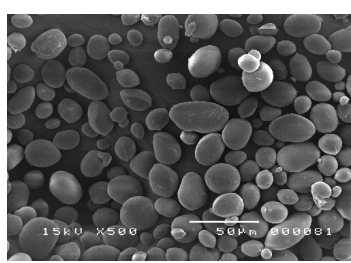

(b)
Fig. 7. Micrograph for (a) Run 2 and (b) Run 5

Using one-way analysis of variance or ANOVA, the Pvalue that was determined was 0.027 which is lower than the $\alpha$-value of 0.05 . This implies that the average particle diameter from runs 1 to 9 varies significantly from each other because of the temperature and velocity settings. The Taguchi Design was used to determine the specific effect of temperature and air velocity on the particle diameter. Figure 12 shows the plot generated for Taguchi Design which shows that the particle diameter increases at lower temperature and decreases at higher temperature. In terms of velocity, higher velocity means an increase in average particle diameter and a lower velocity means a lower average particle diameter. It can also be inferred that the temperature has more effect on the average particle diameter than the air velocity.

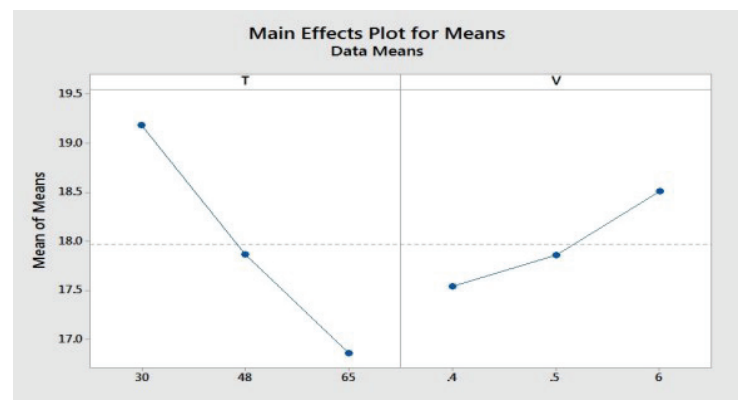

Fig. 8. Effect of Temperature and Velocity on particle diameter

\section{Conclusion}

Modelling and determination of the drying characteristics of the arrowroot starch (Maranta arundinacae) was determined and evaluated using a factorial design of $3^{\mathrm{k}}$. The initial moisture content was determined to have a value of $49.4 \%$ due to the arrowroot samples used which were not fully grown. At higher temperatures, the drying time for the samples were shorter compared to those operating at lower temperatures. Air velocity has little or negligible effect to the drying time and drying rate. The drying rate of arrowroot starch is therefore a function of temperature and time, and the drying curves of arrowroot starch has no constant rate period and only has steady falling rate period. The Midili Model was found to be the best fit model for drying of arrowroot starch since it yielded the highest $\mathrm{R}^{2}$ values and lowest RSME values for all runs. Using scanning electron microscopy, the average particle diameters of arrowroot starch was determined to have a range of $12.06-24.60 \mu \mathrm{m}$ and have an oval shape with an off - center hilum. Using one - way analysis of variance, it was found that the average particle diameters for each run, varies significantly with each other. Lastly, with the aid of the Taguchi Design, it was determined that higher temperatures correspond to lower average particle diameter, while higher velocity corresponds to higher average particle diameters.

\section{References}

1. Alcaraz, J.M., Capati, A.M. \& Alipio, J.E.C.S, (2011).

2. Jyothi, A. N., Sheriff, J. T., \& Sajeev, M. S., Journal of food science, 74(2), (2009).

3. Charles, A. L., Cato, K., Huang, Y., Ciou, J., Chang, J., \& Lin, H. (2015), Food Hydrocolloids, 53, 187191

4. Earle, R. L., Unit Operations in Food Processing, New Zealand Institute of Food Science and Technology, Inc., (1983).

5. Guine, R. P. F., Pinho, S. \& Barroca, M. J., Food and Bioproducts Processing, 89, 422 - 428, (2011).

6. Idlimam, A., Kane, C. S. E. \& Kouhila, M., Revue des Energies Renouvelables, 10(2), 191 - 203, (2007).

7. Rahman, S. N. F. S. A., Wahid, R., \& Rahman, N. A., Procedia - Social and Behavorial Sciences, 195, 2731-2741, (2015).

8. Ukpabi, U. J., Ukenye, E., \& Olojede, A. O., Journal of Food Technology, 7(4), 135-138, (2009).

9. Snyder, E. M., Industrial Microscopy of Starches, p. 661 in Starch: Chemistry and Technology, 2nd ed., Academic Press, New York, N.Y., (1984).

10. Wilhelm, L.R., Suter, D.A. \& Brusewitz, G.H., American Society of Agricultural Engineers. 259 284, (2005).

11. Alibas, I., Journal of Biological and Environmental Sciences, 6(17), (2012). 